\title{
Analysis of Ac Transmission from Desert-Area Large-Scale Photovoltaic Generation
}

\author{
Alsalem Mohammed Hassan, Junichi Arai \\ Electrical Engineering and Electronics \\ Kogakuin University \\ Tokyo, Japan \\ CM12004@ns.kogakuin.ac.jp
}

\begin{abstract}
Large photovoltaic power generation facilities are expected to be installed in desert areas and provide electricity to rural areas through long cable transmission lines. However, ac transmission networks in such areas are usually inadequate for stable grid operation. One problem to be solved is voltage instability when large photovoltaic power generation facilities are connected to weak power grids. In this paper, two solutions for PV operation are proposed. One is use of the SVC and the other is that of the reactor. By conducting computer simulations on a test system, the proposed solutions are shown to improve ac voltage stability and to be feasible for the PV operation in desert areas.
\end{abstract}

Keywords-component; Photovoltaic generation; SVC; Rector; Voltage stability;

\section{INTRODUCTION}

Solar power is a very promising source of electrical energy. Large areas of the earth surface have abundant sunlight that can be used for photovoltaic power generation. Utilization of solar energy must be considered from the perspective of environmental conservation and fossil fuel shortage.

Photovoltaic (PV) generation converts the light spectrum directly into electrical energy through the use of semi-conducting materials. Photovoltaic generation produces DC power. An inverter is used to connect it to the power systems. A large $\mathrm{PV}$ generation system includes photovoltaic array, DC/AC converters and the associated controllers.

Recent studies suggest that PV generation should become commercially attractive and that large-scale facilities be seen in many regions of the world.

Saudi Arabia is an extremely hot country with tropical conditions throughout the year. Electrical power demand for air conditioning and refrigeration is always high. Major industrial cities and oil-producing areas have adequate power. However, rural areas are often subject to power outages due to poor electric facilities. PV generation is expected to provide a solution to power supply problems in rural areas. This research aims at stabilization of the PV generation in desert areas by installing SVCs and reactors into ac transmission network.

The thorough investigation of power system stability with large-scale PV is an urgent task. One problem to be solved is voltage instability when large photovoltaic

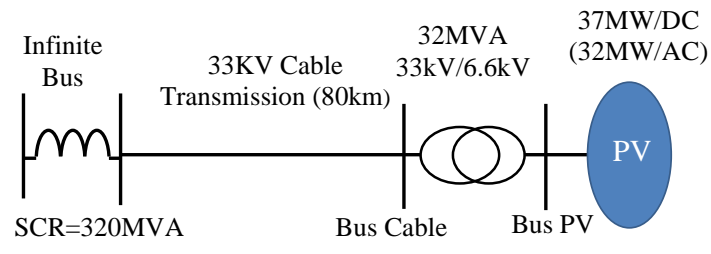

Figure1. Schematic diagram of an aggregated PV generator

power generation facilities are connected to weak power grids.

Moreover, the size and location of large PV generation may cause the determination of power system voltage stability as the PV penetration increases [1] [2].

Fig. 1 shows the configuration of a simplified largescale PV generation system. The SCR (short circuit ratio) is 320MVA in this ac system. The length of this transmission cable is $80 \mathrm{~km}$. A $33 \mathrm{kV}$ underground cable is used because it is more suitable than an exposed overhead line for desert conditions in Saudi Arabia. A 32MW PV generation system would meet the power requirements of a small village.

This study demonstrates the feasibility of a large-scale PV generation system in desert areas.

The ac system is inadequate for PV generation, therefore practical solutions for system voltage control using both SVC and reactor circuits are discussed in this paper.

The MATLAB-SimPowerSystem program is used to verify the effectiveness of the proposed solutions.

\section{SYSTEM CONFIGURATION}

PV capacity of the PV generation is assumed to be $32 \mathrm{MW}$ as stated above. This capacity is derived from the 7MW Ukishima Power Plant (Kawasaki, Japan) and is assumed to be 4.5 times that of the Ukishima facility [3].

The ac bus voltage is $6.6 \mathrm{kV}$. This is identical to that of a conventional distribution network. A 32MVA transformer is connected to a $33 \mathrm{kV}$ cable transmission line.

The previous power flow analysis shows that some sort of voltage control devices are required to keep ac voltage around 1.0 p.u. In this study, we assume both of SVC and reactor are applied for the voltage control. Circuit configuration is shown in Fig. 2a and 2b. 


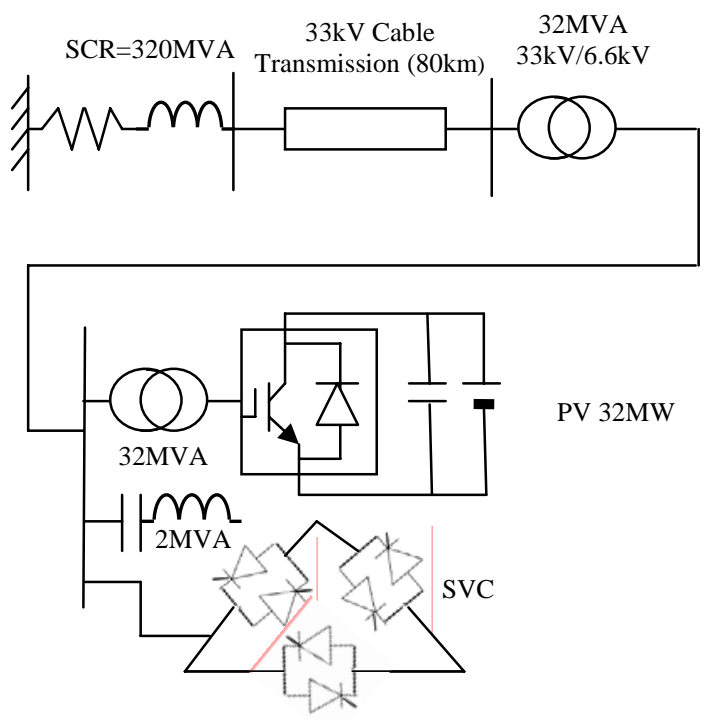

Figure 2a: Aggregated PV generator with SVC

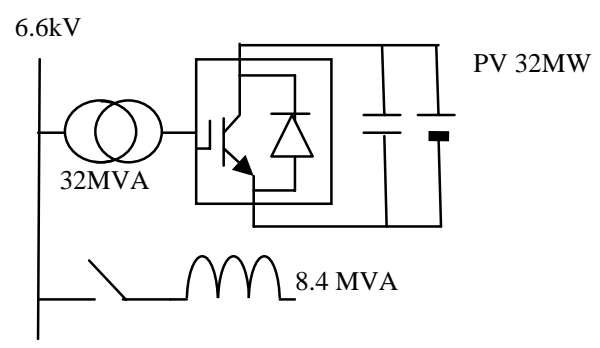

Figure 2b; Aggregated PV generator with reactor

Fig. 2a shows a PV generator circuit with SVC for the voltage control. +6MVA capacitor is used as the PV filter and a -6MVA reactor is used for capacitor compensation they are not shown in Fig.2. A 2MVA filter with a $5^{\text {th }}$ resonant order is used for the SVC.

In Fig. $2 \mathrm{~b}$ an 8.4MVA rector is connected to the circuit as a voltage control device instead of SVC. The reactor regulates the voltage at reference value, $6.6 \mathrm{kV}$ (1.0 p.u.) during the night time operation (PV inactive).

\section{A. Ratings of equipment}

Table 1 shows the rating of equipment used in this study.

\section{B. PV System}

The number of panel is 167,712 . The rated capacity of each panel is $220 \mathrm{~W}$ and the total output is theoretically $37 \mathrm{MW}$. However, it is assumed to be $32 \mathrm{MW}$ when the estimated system loss is taken into consideration.
TABLE II: RATINGS OF EQUIPMENT

\begin{tabular}{|c|c|c|c|}
\hline \multirow{13}{*}{$\begin{array}{c}\mathrm{AC} \\
\text { system }\end{array}$} & \multirow{4}{*}{$\begin{array}{l}\text { Three-phase } \\
\text { voltage source }\end{array}$} & Frequency $(\mathrm{Hz})$ & 60 \\
\hline & & Base voltage $(\mathrm{kV})$ & 33 \\
\hline & & $\begin{array}{l}\text { SCR (short circuit } \\
\text { ratio) (MVA) }\end{array}$ & 320 \\
\hline & & $\mathrm{X} / \mathrm{R}$ ratio & 100 \\
\hline & \multirow[t]{4}{*}{ Cable } & $\begin{array}{l}\text { Total line length } \\
(\mathrm{km})\end{array}$ & 80 \\
\hline & & $\begin{array}{l}\text { Resistor per unit } \\
\text { length }(\mathrm{Ohm} / \mathrm{km})\end{array}$ & 0.015 \\
\hline & & $\begin{array}{l}\text { Inductance per unit } \\
\text { length }(\mathrm{H} / \mathrm{km})\end{array}$ & 0.00049 \\
\hline & & $\begin{array}{l}\text { Capacitance per unit } \\
\text { length }(\mathrm{F} / \mathrm{km})\end{array}$ & $0.46 \times 10^{-6}$ \\
\hline & \multirow[t]{5}{*}{$\begin{array}{l}\text { Substation three- } \\
\text { phase transformer }\end{array}$} & $\begin{array}{c}\text { Primary side voltage } \\
(\mathrm{kV})\end{array}$ & 33 \\
\hline & & $\begin{array}{l}\text { Secondary side } \\
\text { voltage }(\mathrm{kV})\end{array}$ & 6.6 \\
\hline & & Capacity (MVA) & 32 \\
\hline & & Reactance (\%) & 5 \\
\hline & & Resistance (\%) & 0.05 \\
\hline \multirow[t]{10}{*}{ PV } & \multirow[t]{2}{*}{ PV model } & $\begin{array}{l}\text { DC voltage source } \\
(\mathrm{V})\end{array}$ & 400 \\
\hline & & Capacitance C (F) & 0.1 \\
\hline & \multirow[t]{2}{*}{ IGBT inverter } & $\begin{array}{c}\text { Snubber resistance } \\
\operatorname{Rs}(\Omega)\end{array}$ & 1000 \\
\hline & & $\operatorname{Ron}(m \Omega)$ & 0.1 \\
\hline & \multirow[t]{4}{*}{$\begin{array}{c}\text { Inverter } \\
\text { transformer }\end{array}$} & $\begin{array}{c}\text { Primary side voltage } \\
(\mathrm{kV})\end{array}$ & 6.6 \\
\hline & & $\begin{array}{l}\text { Converter side } \\
\text { voltage }(\mathrm{V})\end{array}$ & 210 \\
\hline & & $\begin{array}{c}\text { Transformer capacity } \\
\text { (MVA) }\end{array}$ & 32 \\
\hline & & Reactance (\%) & 5 \\
\hline & \multirow[t]{2}{*}{ Filter } & Inductive (MVA) & 6 \\
\hline & & Capacitance (MVA) & 6 \\
\hline \multirow[t]{8}{*}{ SVC } & Capacity & \multicolumn{2}{|c|}{$0 \sim 11$ MVA (Lag) } \\
\hline & TCR & Inductance $(\mathrm{H})$ & $26.6 \times 10^{-3}$ \\
\hline & \multirow[t]{3}{*}{ Thyristor } & Resistance Ron ( $\Omega$ ) & 0.001 \\
\hline & & $\begin{array}{c}\text { Snubber resistance } \\
(\Omega)\end{array}$ & 500 \\
\hline & & $\begin{array}{c}\text { Snubber capacitance } \\
\text { Cs (F) }\end{array}$ & $250 \times 10^{-9}$ \\
\hline & \multirow[t]{3}{*}{ Harmonic filter } & $\begin{array}{c}\text { Nominal reactive } \\
\text { power (MVA) }\end{array}$ & 2 \\
\hline & & $\begin{array}{c}\text { Resonant frequency } \\
(\mathrm{Hz})\end{array}$ & 300 \\
\hline & & Quality factor (Q) & 50 \\
\hline Reactor & \multicolumn{2}{|c|}{ Inductive (MVA) } & 8.4 \\
\hline
\end{tabular}

In a grid-connected PV system, inverters are required to convert PV dc power output to ac power output for delivery to the utility network. Dc capacitance (smoothing capacitance) applied to the inverter input voltage is $0.1 \mathrm{~F}$. The inverter transformer converts the $210 \mathrm{~V}$ to $6.6 \mathrm{kV}$.The $6.6 \mathrm{kv}$ voltage is boosted to $33 \mathrm{kV}$ by the power transformer. The rated capacity of the transformer is 32MVA, $6.6 \mathrm{kV} / 220 \mathrm{~V}, 5 \% \mathrm{Z}$. The capacity of the filter (Capacitor) is $+6 \mathrm{MVA}$.

The SCR is 320MVA at the cable connection point. This is precisely 10 times the PV generation capacity. The SCR value is $54.8 \mathrm{MVA}$ at the $6.6 \mathrm{kV}$ bus. Therefore, the $\mathrm{SCR} / \mathrm{PV}$ ratio is 1.71 (54.8MVA/32MW). This means that 
the PV generation is connected to a very weak ac system. The improvement of voltage stability of the ac system is extremely important for reliable operation of the PV generation.

\section{SVC}

The capacity of SVC is determined by referring the previous power flow study ( $0 \sim 10 \mathrm{Mvar})$. The inductive operation is required due to excess cable capacitance. Fig. 3 shows the SVC configuration. The SVC regulates ac voltage by increasing or decreasing reactive power. The inductance of TCR (thyristor controlled reactor) is calculated using the following formula. It is necessary to take the estimated inductive capacity margin into account. By considering the margin of $1 \mathrm{Mvar}$, the capacity of the SVC is determined to be 13MVA in design.

$$
\mathrm{L}=\frac{3}{2 \pi 60}\left(\frac{6.6 k V^{2}}{13 M V A}\right)=26.6 m \mathrm{H}
$$

Parameters of the filter (2MVA, 5th resonant order) are calculated as follows;

$$
\begin{gathered}
\mathrm{L}=\frac{1}{2 \pi 60}\left(\frac{6.6 \mathrm{kV}^{2}}{2 M V A\left(1-5^{2}\right)}\right)=2.4 \mathrm{mH} \\
C=\frac{1}{(5 \times 2 \pi 60)^{2} \times L}=\frac{1}{(5 \times 377)^{2} \times 2.4 m H}=117.3 \mu \mathrm{F} \\
R=\frac{n w L}{Q}=\frac{5 \times 2 \pi 60 \times 2.4}{50}=0.09 \Omega
\end{gathered}
$$

\section{Control block}

The PV control block is shown in Fig. 4a and 4b [4] [5] [6]. The input signals of this controller are three phase voltages and three phase currents flowing through the inverter ac side. The output of this controller is On and Off pulses for the PV inverter. This regulates active power $\mathrm{P}$ and reactive power $\mathrm{Q}$ corresponding to the prescribed reference values, Pref and Qref. Pref covers from 0 p.u. to 1 p.u. Qref is usually assigned to 0 p.u because the power factor is operated at 1.0 in the normal operation.

The SVC control block is shown in Fig. 4c. It has a 3phase voltage input and 6 on-pulses for thyristors as output. A measured bus voltage is compared with a given reference voltage value 1.0 p.u.

Fig. 4d shows control blocks of active power control and ac voltage control of $\mathrm{PV}$ applied to with reactor operation.

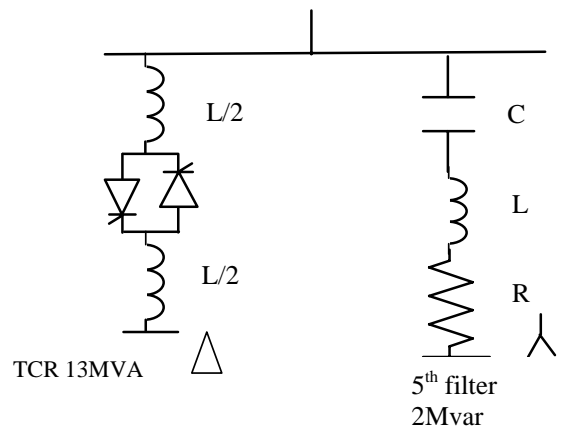

Figure 3: SVC configuration

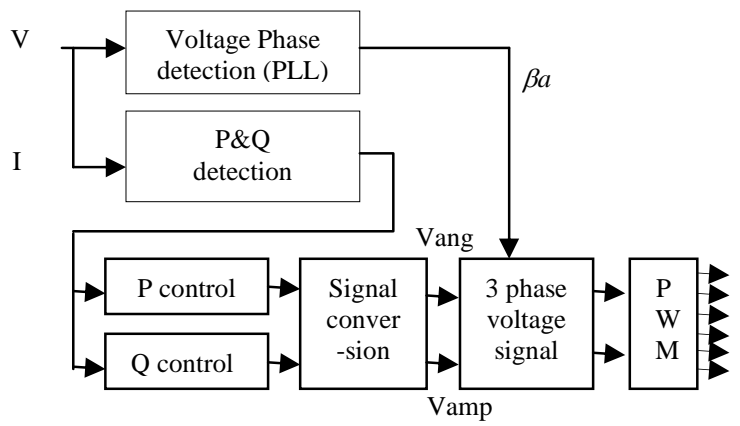

Figure 4a: Control block
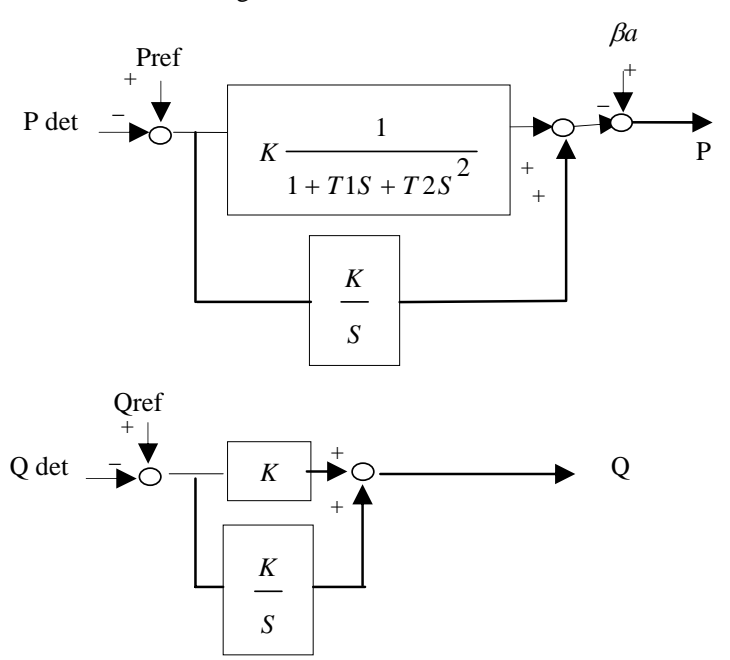

Figure 4b: P\&Q Control block of PV

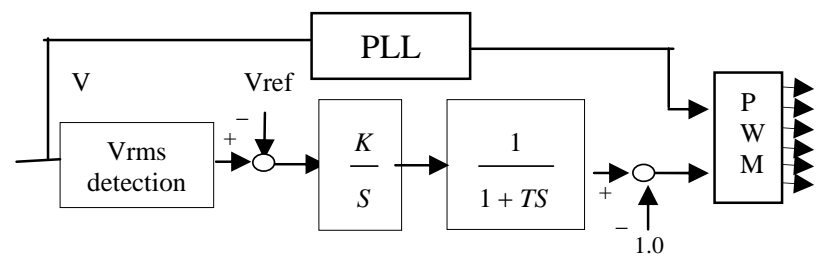

Figure 4c: SVC Control block 

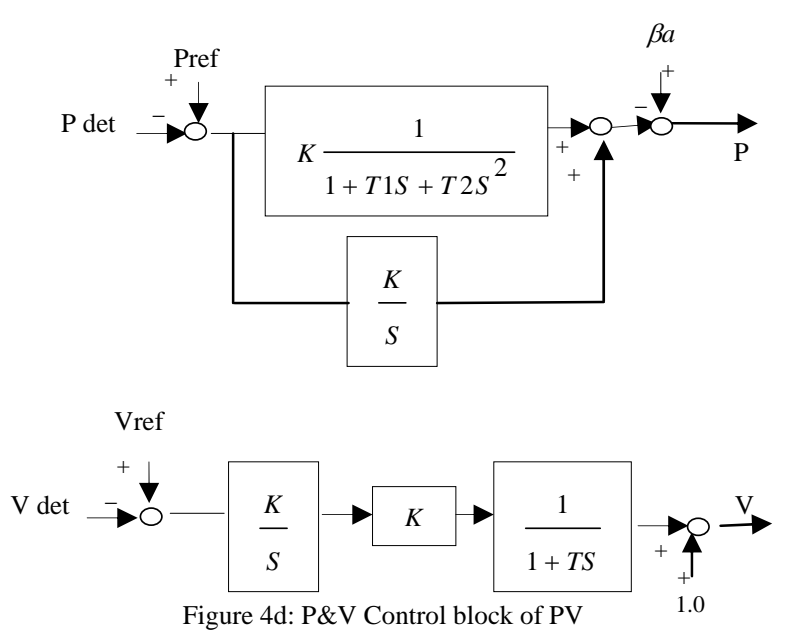

III. StUdy AND EVAlUATION

\section{A. Simulation results}

\section{1) PV with SVC operation}

a) $P V$ power of 0.9p.u.

Fig. 5 shows results of the network operation when both the PV and SVC are in operation. Fig. 5a shows that the ac voltage settles down to 1.0 p.u. which is maintained by the absorption of 0.29p.u. (SVC base) of reactive power provided by the SVC. Fig. 5b shows the behavior of the SVC reactive power and the firing angle, which is 29 degrees, as shown in Fig. 5c.

PV reactive power reaches 0 p.u. as shown in Fig. $5 d$ and PV active power reaches 0.9 p.u. as shown in Fig. 5 e. These results are satisfied with the desired operational purposes.

b) Step PV power change to 1.0p.u.

System stability is usually checked by using a small step change compared to a prescribed reference value. In this study, the step change is assumed to be from 0.9 p.u. (the reference value Pref) to 1.0 p.u.. Fig. 6a, 6b, 6c, and $6 \mathrm{~d}$ show the responses of electric valuables caused by this step change. Fig. 6a shows the voltage briefly falls below 1 p.u. after 2 seconds before returning to 1 p.u.. In this case, the system is stable. The reactive power of PV stays around 0p.u. The ac voltage is well controlled by SVC and stays at 1.0 p.u.. Fig. $6 \mathrm{~b}$ shows the SVC reactive power.

Fig. 6c shows the reactive power for PV momentarily increases from 0.0 p.u. to a slightly higher value for 2 seconds and 3 seconds (without further step voltage increase), the reactive power is stabilized at 0 p.u..

Fig. 6d shows the PV active power increases from 0.9 p.u. to 1.0 p.u. in 2 seconds with a small damped swing.

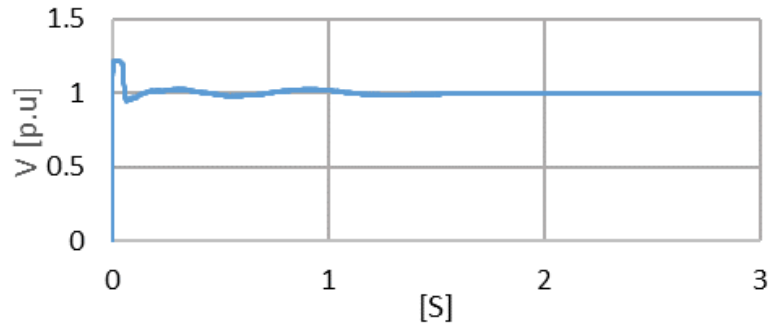

Figure 5a: Voltage

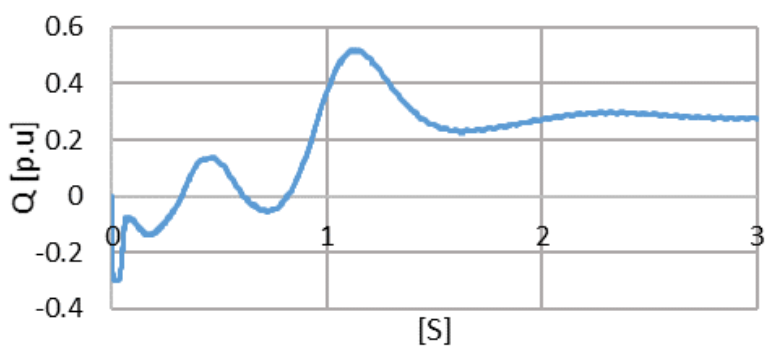

Figure 5b: SVC reactive power
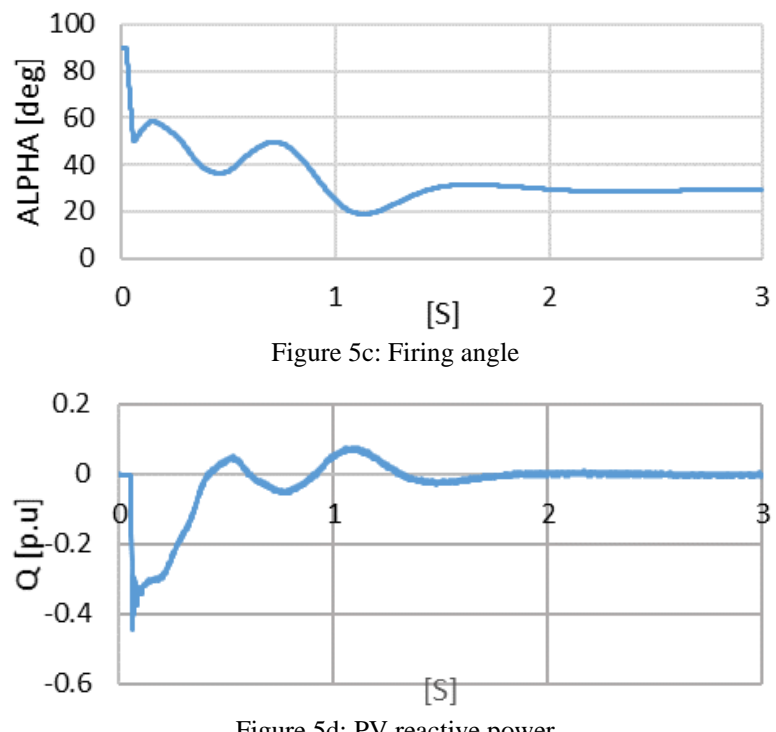

Figure 5d: PV reactive power

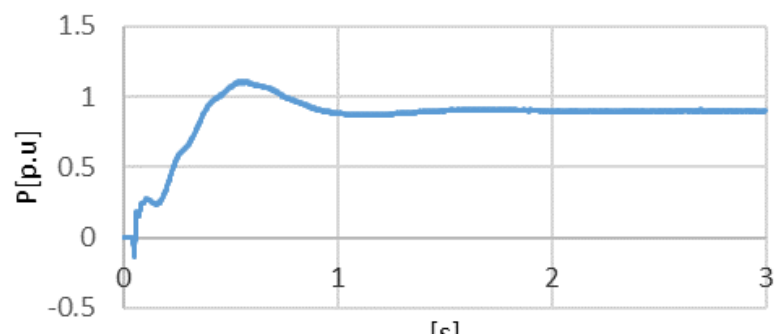

[s]

Figure 5e: PV active power [Figure 5: PV operation with SVC] 

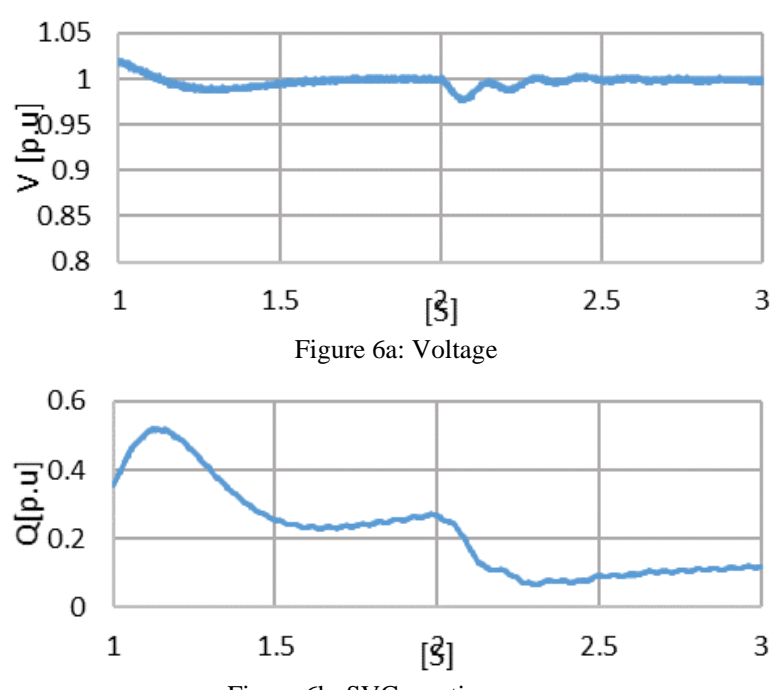

Figure 6b: SVC reactive power

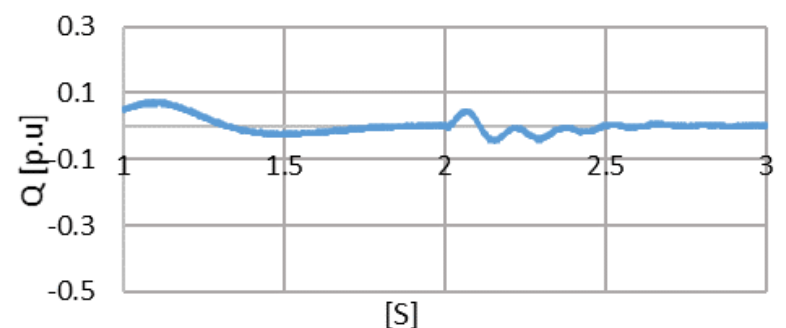

Figure 6c: PV reactive power

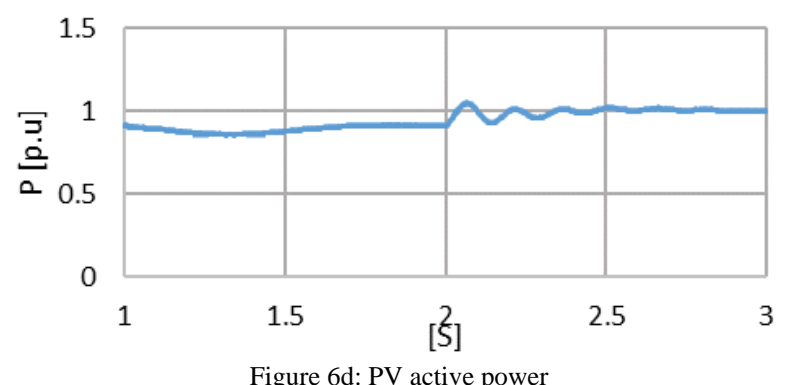

Figure 6: PV operation with SVC (PV power change to 1.0p.u.)

\section{2) PV with Rector}

The PV inverter is capable of generating reactive power. It is considered that PV reactive power control is better than SVC control. The inverter operation is conducted only in the day-time and is not expected to be carried out in the night time. Therefore, the reactor must absorb excess cable capacitance. The reactor capacitance was determined using an SVC operation simulation without PV generation. It was 8.4 Mvar.

a) PV power of 1.0p.u.
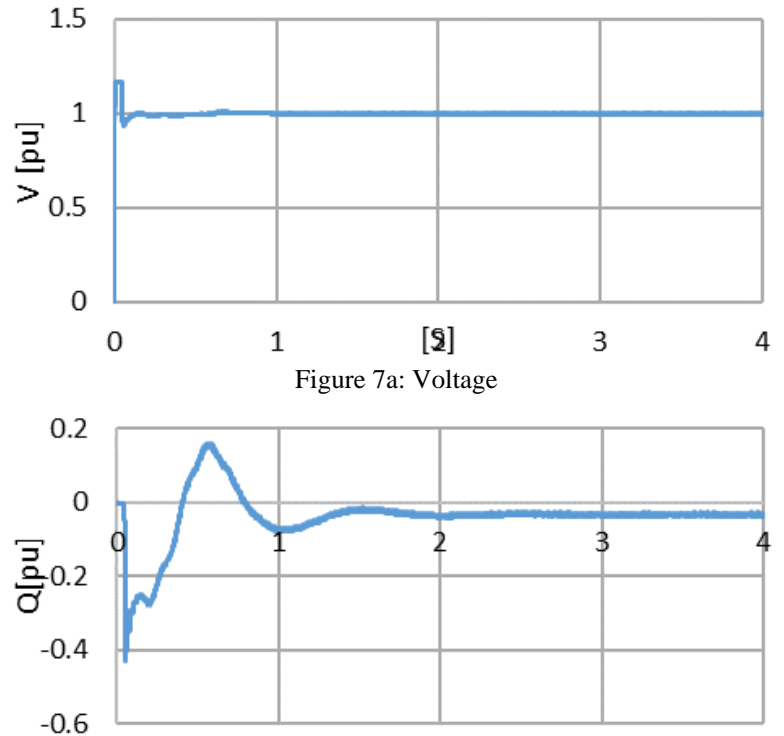

[S]

Figure 7b: Reactive power

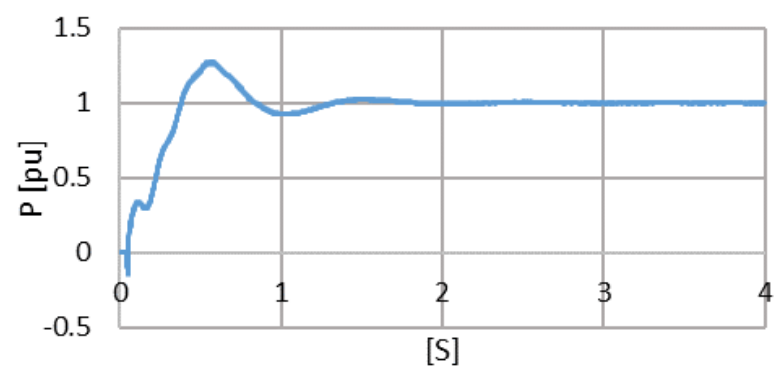

Figure 7c: Active power

Figure 7: PV operation with reactor disconnect

Fig. 7 shows simulation results of Pref $=1.0$ p.u. when the ac voltage is controlled by the PV inverter with the reactor disconnected.

Fig. 7a, 7b, and 7c show the responses of the ac voltage, PV reactive power, and $\mathrm{PV}$ active power respectively. The ac voltage is well-controlled while PV active power is maintained at 1.0p.u. This demonstrates that PV generation with a reactor is practical.

b) Voltage deviation with reactor disconnected

The reactor is connected only at night. When the PV starts to generate power early in the morning, the reactor must be disconnected.

Fig. 8 shows the simulation results when Pref is set to 0.1 p.u. and the reactor is disconnected.

Fig. 8a shows that the ac voltage change is minimal. Fig. 8b shows that PV reactive power changes are directly proportional to changes in reactor values. Fig. 8c shows active power changes roughly around 0.1 p.u. However, active power soon returns to its previous level. 

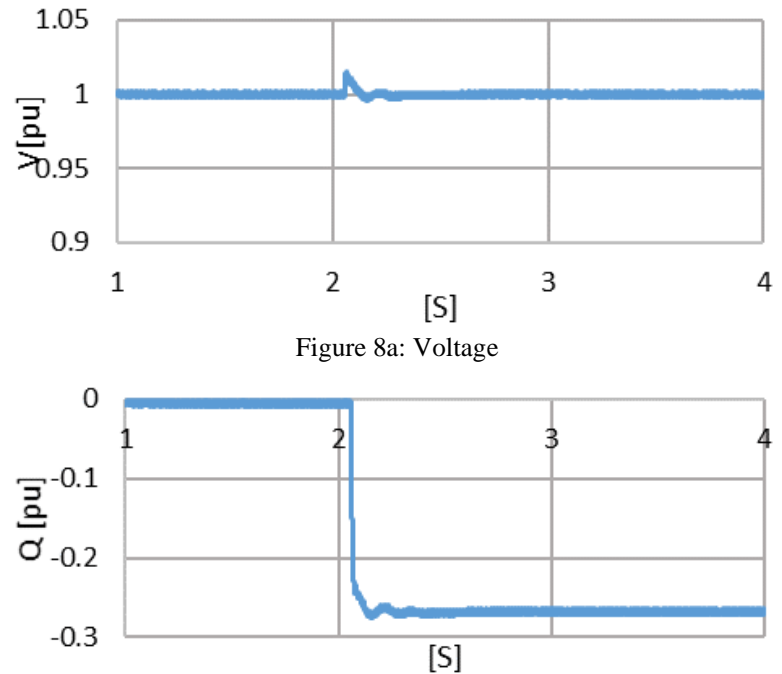

Figure 8b: Reactive power

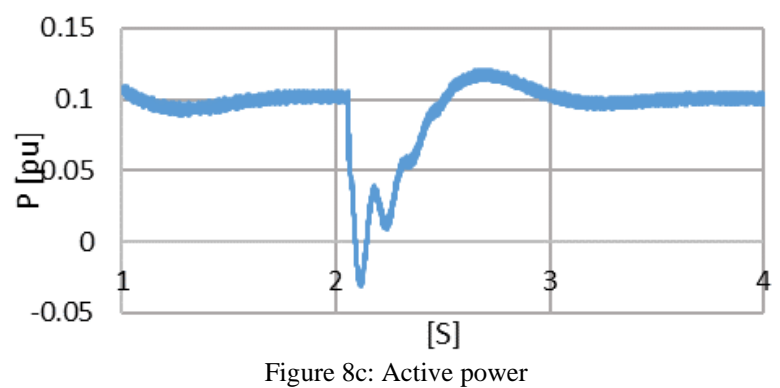

[Figure 8: PV operation with reactor]

In this paper we have examined whether the application of the proposed reactor to the PV generation is feasible.

\section{B. Evaluation}

The PV with the SVC is the best configuration to connect the PV to the weak AC system. However, in the operation of the PV with a SVC, the voltage is controlled even during the night time operation and this makes it costly. The PV with a reactor alone is also possible to operate and has an advantage in cost of its construction and operation. On the other hand, there are two disadvantages in the configuration of the PV with a rector. One is that larger inverter capacity is required to generate sufficient reactive power. However, this is not a major problem for this application, because the total reactive power was less than $5 \%$. The other is that ac voltage is not controlled during the night time operation due to fixed reactance. If the load remains constant, this would not be a problem.

\section{CONCLUSION}

A large-scale PV system connected to a weak ac system was studied. From this study, we conclude that the PV operation becomes stable when the ac voltage fluctuation is mitigated.

We propose two solutions for PV operation. One is use of the SVC and the other is that of the reactor. Conducting computer simulations show the proposed solutions are feasible for the PV operation in desert areas.

\section{REFERENCES}

[1] Photon International, The Solar Power Magazine, April, 2011, http://www.photonmagazine.com.

[2] Y. -B. Wang, C. -S. Wu, H. Liao, and H. -H. Xu, " Study on impacts of large-scale photovoltaic power station on power grid voltage profile," in Third International Conference on Electric Utility Deregulation, Restructuring and Power Technologies, 2008.

[3] Press Release (Aug 10,2011) Commencement of Operation of Ukishima Solar Power Plant Promoting one of the largest solar power projects in Japan at coastal area of Kawasaki Cityhttp://www.tepco.co.jp/en/press/corp-com/release/11081005e.html

[4] Tooru Morii, Junichi Arai, Tsumenaga Masahiro, "Stability Analysis of Inverter for Renewable Energy", 12th WSEAS International Conference on Electric Power Systems, High Voltages, Electric Machines (POWER '12), 68503-022, Prague, Czech, September 24-26, 2012.

[5] Junichi Arai, Wataru Kuwabara, Ryo Tanaka, Ryuichi Yokoyama, "Control of Dc Transmission System from a Wind Farm, No.899, p12237-12242, Miran, IFAC 18 ${ }^{\text {th }}$ World Congress, 2012.

[6] Junichi Arai, Kenji Iba, Toshihisa Funabashi, Yosuke Nakanishi, Kaoru Koyanagi, and Ryuichi Yokoyama, "Power Electronics and its Application to Renewable Energy in Japan”, IEEE Circuit and Systems Magazine, Vol. 8, No. 3, 2008, pp52-66. 